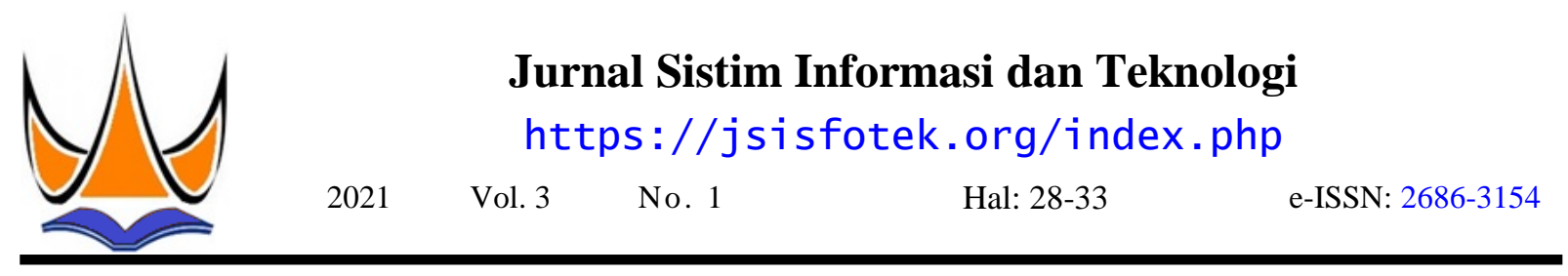

\title{
Akurasi Pemetaan Kelompok Belajar Siswa Menuju Prestasi Menggunakan Metode K-Means
}

\author{
Sri Dewi ${ }^{1 \bowtie}$, Sarjon Defit ${ }^{2}$, Yuhandri Yunus ${ }^{3}$ \\ ${ }^{1,2,3}$ Universitas Putra Indonesia YPTK Padang \\ srid305@gmai1.com
}

\begin{abstract}
The quality of students in school has a lot of diversity, this makes students have different levels of understanding. This can be seen from the variety of student scores obtained on report card scores, this needs to be a concern for the school, especially teachers. One of them is by forming effective study groups so that every student has the opportunity to excel. So this research was carried out with the aim of helping schools, especially teachers, to map student study groups evenly based on student report cards obtained in Semester I to Semester IV. The method used was clustering with the K-Means algorithm on the report card scores of Class IX.C students at SMP Pembangunan Laboratorium UNP. The results in this study obtained 3 clusters of students, namely students with High Achievement, Achievement and Less Achievement. This research can be used as a guide for teaching teachers in making decisions about the formation of student study groups in Class IX.C.
\end{abstract}

Keywords: K-Means Clustering, Centroid, Groups, Achievements, Student Grades.

\begin{abstract}
Abstrak
Kualitas siswa dalam belajar di sekolah memiliki banyak keragaman hal ini membuat siswa memiliki tingkat pemahaman yang berbeda-beda ini dapat dilihat dari ragamnya nilai siswa yang didapatkan pada nilai rapor, ini perlu menjadi perhatian bagi pihak sekolah khususnya guru. Salah satunya dengan membentuk kelompok belajar yang efektif agar setiap siswa mempunyai kesempatan untuk berprestasi. Maka dilakukan penelitian ini dengan tujuan membantu sekolah khususnya guru unutk memetakan kelompok belajar siswa secara merata berdasarkan nilai rapor siswa yang didapat pada Semester I sampai dengan Semester IV. Metode yang digunakan adalah Clustering dengan algoritma K-Means terhadap data nilai rapor siswa Kelas IX.C di SMP Pembangunan Laboratorium UNP. Hasil dalam penelitian ini mendapatkan 3 cluster siswa, yaitu siswa Sangat Berprestsi, Berprestsi dan Kurang Berprestsi. Penelitian ini dapat dijadikan sebagai pedoman bagi guru pengajar dalam pengambilan keputusan terhadap pembentukan kelompok belajar siswa di Kelas IX.C.
\end{abstract}

Kata kunci: K-Means Clustering, Centroid, Kelompok, Prestasi, Nilai Siswa.

(C) 2021 JSisfotek

\section{Pendahuluan}

Pendidikan merupakan suatu cara pembelajaran untuk meningkatkan pengetahuan, sikap dan keterampilan seseorang. Sekolah menjadi sarana berlangsungnya pendidikan secara langsung, dengan bertemunya guru dan siswa [1]. Kualitas siswa dalam belajar di sekolah memiliki banyak keragaman hal ini membuat siswa memiliki tingkat pemahaman yang berbeda-beda, ini perlu menjadi perhatian bagi pihak sekolah khususnya guru selaku pengajar dan pendidik siswa di sekolah. Salah satunya dengan membentuk kelompok belajar yang efektif agar setiap siswa mempunyai kesempatan untuk berprestasi. Belajar kelompok merupakai proses transfer ilmu yang melibatkan lebih dari satu orang, dimana orang yang satu dengan orang yang lain saling melengkapi dan bertukar fikiran. Dengan menerapkan sistem belajar kelompok dapat mengurangi tingkat kesulitan belajar siswa di sekolah.

Data Mining bukanlah suatu bidang yang sama sekali baru [2]. Data Mining bukanlah bidang ilmu yang berdiri sendiri, tetapi sangan berkaitan dengan bidang ilmu yang lain seprti: database, statistik, pencarian informasi dan artificial intellegent [3]. Data Mining merupakan proses untuk menemukan pengetahuan (Knowledge Discovery) yang ditambang dari sekumpulan data yang volumenya sangat besar [4], dan dapat membantu dalam mengambil keputusan [5]. Data Mining adalah metode Clustering dengan algoritma KMeans [6]. Clustering merupakan aktivitas (task) yang bertujuan mengelompokkan data yang memiliki kemiripan antara satu data dengan data lainnya ke dalam klaster sehingga data dalam satu klaster memiliki tingkat kemiripan yang maksimum dan data antar klaster memiliki kemiripan yang minimum [7].

Algoritma K-Means dapat membantu menyelesaikan sistem pembagian kelompok [8]. K-Means merupakan salah satu metode pengelompokan data nonhierarki (sekatan) yang berusaha mempartisi data yang ada ke dalam bentuk dua atau lebih kelompok. Metode ini mempartisi data ke dalam kelompok sehingga data berkarakteristik sama dimasukkan ke dalam satu kelompok yang sama dan data yang berkarakteristik berbeda dikelompokkan kedalam kelompok yang lain [9]. K-Means menambang data tanpa proses pengawasan dan memiliki kecepatan pengolahan data. Jumlah cluster pada K-Means ditentukan oleh pengguna dan sensitive terhadap centroid awal [10].

Diterima: 07-10-2020 | Revisi: 21-10-2020 | Diterbitkan: 31-03-2021 | DOI: 10.37034/jsisfotek.v3i1.40 
Penelitian terdahulu tentang algoritma K-Means 2.1. Mengidentifikasi Masalah

Clustering pernah dilakukan oleh Luka, dkk (2019) juga melakukan penelitian menggunakan algoritma $\mathrm{K}$ Means tentang analisis pembentukan kelompok diskusi panel siswa. Menggunakan algoritma terbaik hasil perbandingan algoritma Fuzzy C-Means dan K-Means. Hasil dari penelitian ini adalah Komposisi kelompok yang terbentuk dari algoritma K-Means dengan maksimal anggota sebanyak 5 oarang [11].

Pada tahap ini dilakukan proses mendeskripsikan masalah, menganalisa masalah serta memahami masalah tersebut sehingga didapatkan solusi dan penyelesaian masalah.

2.2. Tujuan Penelitian

Tujuan yang ingin dicapai pada penelitian ini adalah menentukan cluster siswa dalam pemetaan kelompok Khakim, dkk (2020) juga menerapkan algoritma K- belajar berdasarkan nilai rapor Semester I sampai Means untuk Analisa Jaringan Dokumentasi dan dengan Semester IV sebanyak 3 cluster, yaitu (K1) Informasi Hukum Kementerian Tentang Teknologi Sangat Berprestasi, (K2) Berprestasi dan (K3) Kurang Informasi. Dataset peraturan diambil dari website JDIH Berprestasi.

masing-masing kementerian. Dari hasil analisis didapatkan total 28 JDIH Kementerian. Cluster 1 berisi 12 kementerian, Cluster 2 berisi 13 Kementerian, Data yang digunakan dalam penelitian ini adalah data Cluster 3 berisi 2 Kementerian, dan Cluster 4 berisi 1 nilai rapor siswa Semester I sampai dengan Semester Kementerian [12]. Algoritma K-Means juga diterapkan IV Kelas IX.C di SMP Pembangunan Laboratorium oleh peneliti Rachman, dkk (2019) untuk pemetaan UNP. Data didapatkan melalui pengambilan file dan kinerja Dosen PPNS dengan kriteria EPD. Data yang melakukan wawancara dengan pihak sekolah.

diolah dalam penelitian ini adalah data hasil Indeks Prestasi Dosen (IPD) yang diisi oleh mahasiswa pada tahun ajaran 2017/2018. Berdasarkan hasil penelitian yang telah dilakukan didapatkan empat cluster dengan masing-masing nilai rata-rata EDP $3,11,3,37,3,58,3,8$
[13]. Priyatman (2020) melakukan penelitian untuk memprediksi waktu kelulusan mahasiswa. Algoritma kMeans dalam data mining sudah berhasil diterapkan dengan menghasilkan 4 jenis cluster [14]. Pengklasteran mahasiswa untuk kepentingan akademis juga pernah dilakukan oleh peneliti-peneliti sebelumnya [15][16][17][18].

\section{Metodologi Penelitian}

Agar penelitian berjalan dengan baik, maka diperlukan

kerangka kerja dari penelitian. Kerangka penelitian merupakan tahapan-tahapan yang dilakukan dalam menyelesaikan penelitian. Adapun kerangka kerja penelitian dapat dilihat pada Gambar 1.

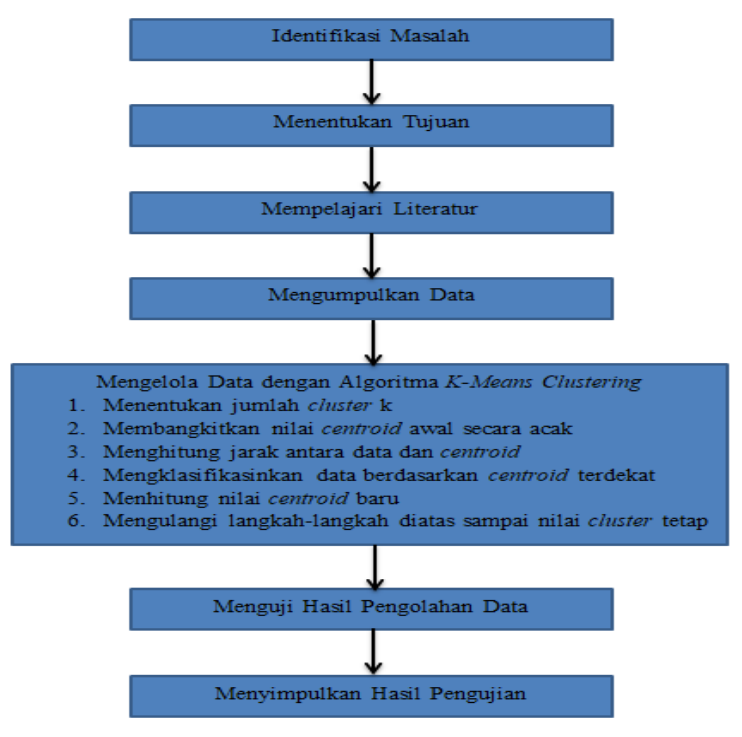

2.4. Mengolah Data dengan Algoritma K-Means
Clustering

Langkah-langkah mengolah data dengan Algoritma KMeans Clustering adalah:

1. Menentukan jumlah cluster K. Jumlah cluster tergantung pada kebutuhan sistem.

2. Menentukan nilai titik tengah (centroid) secara acak sebanyak jumlah cluster.

3. Alokasikan masing-masing data ke pusat cluster terdekat, dengan rumus:

$B e=\sqrt{ }\left(\left(\mathrm{O}_{\mathrm{i}}-\mathrm{T}_{\mathrm{i}}\right)^{\wedge} 2+\left(\mathrm{O}_{\mathrm{j}}-\mathrm{T}_{\mathrm{j}}\right)^{\wedge} 2\right)$

\section{Dimana:}

$B \mathrm{e}=$ Jarak data ke pusat cluster ;

$\mathrm{O}=$ Data record;

$\mathrm{T}=$ Data centroid;

4. Hitung ulang pusat cluster (centroid) baru, dengan rumus:

$\mathrm{KI}=(\mathrm{O} 1+\mathrm{O} 2+\mathrm{O} 3+\cdots+\mathrm{On}) /\left(\sum \mathrm{O}\right)$

Dimana :

$\mathrm{K} 1$ = Centroid baru ;

$\mathrm{O} 1$ = Nilai data record $\mathrm{ke}-1$;

On = Nilai data record ke-n ;

$\sum \mathrm{O}=$ Jumlah data record $;$

5. Alokasikan kembali data ke pusat cluster yang baru didapatkan. Jika pusat cluster masih mengalami perubahan, maka proses diulangi dari langkah 3, tetapi jika pusat cluster tidak mengalami perubahan, maka proses pencarian dihentikan.

Gambar 1. Kerangka Kerja Penelitian

2.5. Menguji Hasil Pengolahan Data

Jurnal Sistim Informasi dan Teknologi Vol. 3 No. 1 (2021) 28-33 
Menguji hasil pengolahan data bertujuan untuk mendapatkan keakuratan dengan sistem sehinggan dapat berjalan dengan baik dan sesuai dengan tujuan penelitian. Dilakukan dengan langkah sebagai berikut:

a. Menyediakan data dalam bentuk excel yang akan digunakan dalam pengujian perangkat lunak;

b. Menentukan tujuan penelitian, yaitu cluster yang dibutuhkan;

c. Menjalankan software Rapid Miner menggunakan data yang sudah didapatkan;

d. Membandingkan hasil yang didapatkan dari perhitungan manual dengan perhitungan menggunakan Rapid Miner.

\subsection{Menyimpulkan Hasil Pengujian}

Kesimpulan diambil berdasarkan hasil perhitungan Algoritma K-Means Clustering manual dengan pengujian menggunakan Rapid Miner, hasil yang didapatkan akan dijadikan rekomendasi dan sebagai bahan pertimbangan dalam pengambilan keputusan.

\section{Hasil dan Pembahasan}

Menentukan pengelompokan siswa berdasarkan nilai rapor siswa Semester I sampai dengan Semester IV untuk memetakan kelompok belajar siswa jumlah sampel data yang diolah dalam penelitian ini berjumlah 25 data siswa dan 10 mata pelajaran yang disajikan pada Tabel 1 .

Tabel 1. Sampel Data Nilai Siswa

\begin{tabular}{|c|c|c|c|c|c|c|}
\hline No & ID & $\begin{array}{c}\text { PEND. } \\
\text { AGAMA }\end{array}$ & $\begin{array}{l}\text { PEND } \\
\text { PPKN }\end{array}$ & $\begin{array}{c}\text { B. } \\
\text { INDO }\end{array}$ & MTK & IPA \\
\hline 1 & 18054 & 87 & 84.25 & 85.75 & 83.5 & 84.25 \\
\hline 2 & 18027 & 84 & 86 & 84.5 & 82 & 82 \\
\hline 3 & 18001 & 87.75 & 87.25 & 85.5 & 83 & 85.75 \\
\hline 4 & 18083 & 86.5 & 87 & 85.25 & 85.75 & 86.25 \\
\hline 5 & 18058 & 83.75 & 79.75 & 82.5 & 81 & 80.75 \\
\hline 6 & 18033 & 85 & 86 & 86.5 & 83.5 & 85.75 \\
\hline 7 & 19165 & 84 & 86.5 & 84 & 84.5 & 87 \\
\hline 8 & 18007 & 84.75 & 85.75 & 84.75 & 84 & 83.5 \\
\hline 9 & 18062 & 91.5 & 88.75 & 88.75 & 86.25 & 87.5 \\
\hline 10 & 18037 & 89.75 & 85.75 & 86.5 & 84.75 & 86 \\
\hline 11 & 18066 & 85.5 & 87.25 & 85.75 & 86.75 & 87.25 \\
\hline 12 & 18038 & 82.5 & 81 & 84 & 83.75 & 82 \\
\hline 13 & 18069 & 86 & 86.75 & 84.25 & 88.75 & 87.75 \\
\hline 14 & 18070 & 85.25 & 86 & 83.25 & 83.25 & 84.75 \\
\hline 15 & 18013 & 85.25 & 86.25 & 87.5 & 80.75 & 85.75 \\
\hline 16 & 18076 & 89.75 & 84.5 & 84.25 & 84.5 & 86.25 \\
\hline 17 & 18017 & 85.75 & 86 & 84.5 & 84.75 & 84.75 \\
\hline 18 & 18018 & 85 & 85.5 & 85.5 & 84.25 & 84 \\
\hline 19 & 18019 & 87.25 & 88 & 86 & 85.5 & 87 \\
\hline 20 & 18047 & 87.25 & 86.25 & 87 & 86.75 & 85 \\
\hline 21 & 18049 & 89.75 & 87.25 & 88.75 & 84.75 & 87.5 \\
\hline 22 & 18050 & 85.5 & 85.5 & 86 & 84.75 & 87 \\
\hline 23 & 18051 & 88.75 & 87 & 84.5 & 84.75 & 85.25 \\
\hline 24 & 18024 & 87.25 & 88.5 & 87.75 & 84.25 & 86.25 \\
\hline 25 & 18025 & 81 & 80.75 & 82.75 & 82.5 & 78.5 \\
\hline
\end{tabular}

a. Menentukan Jumlah Cluster

Jumlah cluster ditentukan berdasarkan tujuan yang akan dicapai. Dalam penelitian ini jumlah cluster dibagi 3 cluster, yaitu (K1) Sangat Berprestasi, (K2) Berprestasi dan (K3) Kurang Berprestasi.

b. Menentukan Titik Centroid Secara Acak
Nilai centroid awal ditentukan secara acak dengan mengambil nilai siswa urutan atas, tengah dan bawah. Data nilai siswa centroid awal dapat dilihat pada Tabel 2.

Tabel 2 Data Centroid Awal

\begin{tabular}{lll}
\multicolumn{1}{c}{ K1 } & \multicolumn{1}{c}{ K2 } & \multicolumn{1}{c}{ K3 } \\
Id: 18038 & Id: 18017 & Id: 18001 \\
\hline 82.5 & 85.75 & 87.75 \\
81 & 86 & 87.25 \\
84 & 84.5 & 85.5 \\
83.75 & 84.75 & 83 \\
82 & 84.75 & 85.75 \\
84.25 & 85.75 & 85.25 \\
86.75 & 85.5 & 85.5 \\
85.75 & 88.75 & 89 \\
84.75 & 88.5 & 87 \\
80 & 85.75 & 87.25 \\
\hline
\end{tabular}

c. Menghitung Jarak Terdekat Data dengan Centroid Iterasi 1 (Pertama)

Untuk menghitung pusat cluster dihitung dari jarak tiap data ke setiap titik centroid menggunakan rumus (1):

\section{Iterasi 1 Cluster 1}

$B_{11}=\sqrt{ }\left((87-82.5)^{\wedge} 2+(84.25-81)^{\wedge} 2+(85.75-84)^{\wedge} 2\right.$

$+(83.5-83.75)^{\wedge} 2+(84.25-82)^{\wedge} 2+(86-84.25)^{\wedge} 2+$

$(84.75-86.75)^{\wedge} 2+(86.5-85.75)^{\wedge} 2+(87.25-824.75)^{\wedge} 2$ $+(88.5-80)^{\wedge} 2=\sqrt{ } 125.13=11.18593$

\section{Iterasi 1 Cluster 2}

$B_{21}=\sqrt{ }\left((87-85.15)^{\wedge} 2+(84.25-85.775)^{\wedge} 2+(85.75-\right.$ $85.225)^{\wedge} 2+(83.5-83.525)^{\wedge} 2+(84.25-875)^{\wedge} 2+(86-$ $86)^{\wedge} 2+(84.75-85.275)^{\wedge} 2+(86.5-87.05)^{\wedge} 2+(87.25-$ $87.375)^{\wedge} 2+(88.5-86.025)^{\wedge} 2=\sqrt{ } 22.813=4.776243$

\section{Iterasi 1 Cluster 3}

$B_{31}=\sqrt{ }\left((87-87.75)^{\wedge} 2+(84.25-85.25)^{\wedge} 2+(85.75-\right.$

$85.5)^{\wedge} 2+(83.5-83)^{\wedge} 2+(84.25-85.75)^{\wedge} 2+(86-$

$85.25)^{\wedge} 2+(84.75-85.5)^{\wedge} 2+(86.5-89)^{\wedge} 2+(87.25-$

$87)^{\wedge} 2+(88.5-87.25)^{\wedge} 2=\sqrt{ } 21.125=4.596194$

Hasil perhitungan nilai Dan selanjutnya akan ditampilkan pada Tabel 3. 
Tabel 3. Pengelompokan Data Pusat Cluster Iterasi 1

\begin{tabular}{|c|c|c|c|c|c|}
\hline No & $\mathrm{C} 1$ & $\mathrm{C} 2$ & $\mathrm{C} 3$ & MIN & Cluster \\
\hline 1 & 11.18593 & 4.776243 & 4.596194 & 4.596194 & 3 \\
\hline 2 & 7.224092 & 6.11351 & 7.084314 & 6.11351 & 2 \\
\hline 3 & 12.41974 & 3.929058 & 0 & 0 & 3 \\
\hline 4 & 12.61448 & 6.388466 & 6.33443 & 6.33443 & 3 \\
\hline 5 & 6.279928 & 12.70827 & 14.58809 & 6.279928 & 1 \\
\hline 6 & 9.813893 & 3.142451 & 4.007805 & 3.142451 & 2 \\
\hline 7 & 10.79352 & 5.332682 & 6.11351 & 5.332682 & 2 \\
\hline 8 & 10.58891 & 4.100305 & 7 & 4.100305 & 2 \\
\hline 9 & 17.60149 & 9.313968 & 7.01338 & 7.01338 & 3 \\
\hline 10 & 13.11726 & 5.830952 & 5.006246 & 5.006246 & 3 \\
\hline 11 & 11.45098 & 4.892596 & 6.154267 & 4.892596 & 2 \\
\hline 12 & 0 & 10.21335 & 12.41974 & 0 & 1 \\
\hline 13 & 14.40052 & 7.352721 & 8.238629 & 7.352721 & 2 \\
\hline 14 & 8.824681 & 4.49305 & 5.830952 & 4.49305 & 2 \\
\hline 15 & 11.50272 & 5.841661 & 4.308422 & 4.308422 & 3 \\
\hline 16 & 11.7047 & 5.0806 & 4.527693 & 4.527693 & 3 \\
\hline 17 & 10.21335 & 0 & 3.929058 & 0 & 2 \\
\hline 18 & 9.117291 & 3.269174 & 4.962358 & 3.269174 & 2 \\
\hline 19 & 13.16719 & 4.776243 & 3.335416 & 3.335416 & 3 \\
\hline 20 & 13.65879 & 5.905506 & 6.860211 & 5.905506 & 2 \\
\hline 21 & 15.67043 & 8.192985 & 6.149187 & 6.149187 & 3 \\
\hline 22 & 11.13272 & 3.724916 & 4.575751 & 3.724916 & 2 \\
\hline 23 & 13.73863 & 4.841229 & 3.952847 & 3.952847 & 3 \\
\hline 24 & 13.19327 & 6.11351 & 4.643544 & 4.643544 & 3 \\
\hline 25 & 5.402546 & 13.61066 & 15.82917 & 5.402546 & 1 \\
\hline
\end{tabular}

Setelah melakukan perhitungan pada iterasi pertama maka didapatkan pengelompokan K1, K2 dan K3 yaitu:

a. Anggota Cluster 1 (K1) terdiri dari 7 siswa dengan nomor urut: $(5,12,25)$.

b. Anggota Cluster 2 (K2) terdiri dari 7 siswa dengan nomor urut: $(2,6,7,8,11,13,14,17,18,20,22)$.

c. Anggota Cluster 3 (K3) terdiri dari 9 siswa dengan nomor urut: $(1,3,4,9,10,15,16,19,21,23,24)$.

\section{Iterasi 7 (Tujuh)}

Iterasi 7 (ketujuh) merupakan iterasi terakhir dalam pengolahan data pemetaan kelompok belajar siswa. Untuk melakukan iterasi ketujuh, perlu menentukan nilai centroid baru. Nilai centroid harus ditentukan dengan cara menghitung rata-rata data pada centroid yang sama dari hasil iterasi sebelumnya yaitu:

a. Anggota Cluster 1 (K1) terdiri dari 3 siswa dengan nomor urut: $(5,12,25)$.

b. Anggota Cluster 2 (K2) terdiri dari 10 siswa dengan nomor urut: $(1,2,6,7,8,14,15,17,18,22)$.

c. Anggota Cluster 3 (K3) terdiri dari 12 siswa nomor urut: $(3,4,9,10,11,13,16,19,20,21,23,24)$.

Nilai centroid baru dihitung untuk iterasi ketujuh berdasarkan hasil iterasi keenam dengan rumus (2).

Cluster 1 (K1) berjumlah 3 siswa pada iterasi 6:

$K_{1 \mathrm{x}}=83.75 / 3+82.5 / 3+81 / 3=82.41666667$

$K_{2 \mathrm{x}}=80.5$

$K_{3 \mathrm{x}}=83.08333333$

$K_{4 \mathrm{x}}=82.41666667$
Cluster 2 (K2) berjumlah 10 siswa pada iterasi 6:

$K_{1 \mathrm{y}}=87 / 10+84 / 10+85 / 10+84 / 10+84.75 / 10+85.25 / 10+8$

$5.25 / 10+85.75 / 10+85 / 10+85.5 / 10=85.15$

$K_{2 \mathrm{y}}=85.775$

$K_{3 \mathrm{y}}=85.225$

$K_{4 y}=83.525$

Cluster 3 (K3) berjumlah 12 siswa pada iterasi 6:

$$
\begin{aligned}
& K_{1 \mathrm{z}}=87.75 / 12+86.5 / 12+91.5 / 12+89.75 / 12+85.5 / 12+86 / \\
& 12+89.75 / 12+87.25 / 12+87.25 / 12+89.75 / 12+88.7 \\
& 5 / 12+87.25 / 12=88.08333333
\end{aligned}
$$

$K_{2 \mathrm{z}}=87.02083333$

$K_{3 \mathrm{z}}=86.1875$

$K_{4 \mathrm{z}}=85.47916667$

Berdasarkan perhitungan di atas, maka diperoleh nilai centroid baru untuk iterasi ketujuh seperti pada Tabel 4.

Tabel 4. Data Centroid Baru

\begin{tabular}{llll}
\hline No & K1x & K1y & K1z \\
\hline 1 & 82.41666667 & 85.15 & 88.08333333 \\
2 & 80.5 & 85.775 & 87.02083333 \\
3 & 83.08333333 & 85.225 & 86.1875 \\
4 & 82.41666667 & 83.525 & 85.47916667 \\
5 & 80.41666667 & 84.875 & 86.47916667 \\
6 & 83.5 & 86 & 87.5 \\
7 & 84.91666667 & 85.275 & 86.375 \\
8 & 84.91666667 & 87.05 & 88.47916667 \\
9 & 85.41666667 & 87.375 & 86.91666667 \\
10 & 79.33333333 & 86.025 & 87.125 \\
\hline
\end{tabular}

Hitung kembali jarak data dengan centroid untuk semua data ke setiap titik pusat baru untuk menghitung iterasi yang ke-7 ditentukan dengan rumus (1):

Titik pusat untuk Cluster 1 (K1) pada iterasi ke 7.

$B_{11}=\sqrt{ }\left((87-82.41666667)^{\wedge} 2+(84.25-80.5)^{\wedge} 2+(85.75-\right.$

$83.08333333)^{\wedge} 2+(83.5-82.41666667)^{\wedge} 2+(84.25-$

$80.41666667)^{\wedge} 2+(86-83.5)^{\wedge} 2+(84.75-84.91667)^{\wedge} 2$

$+(86.5-84.91666667)^{\wedge} 2+(87.25-85.41666667)^{\wedge} 2$

$+(88.5-79.33333333)^{\wedge} 2=\sqrt{ } 154.22222=12.418624$

Titik pusat ke-2 untuk Cluster 2 (K2) pada iterasi 7

$B_{21}=\sqrt{ }\left((87-85.15)^{\wedge} 2+(84.25-85.775)^{\wedge} 2+(85.75-\right.$ $85.225)^{\wedge} 2+(83.5-83.525)^{\wedge} 2+(84.25-84.875)^{\wedge} 2+(86-$ $86)^{\wedge} 2+(84.75-85.275)^{\wedge} 2+(86.5-87.05)^{\wedge} 2+(87.25-$ $87.375)^{\wedge} 2+(88.5-86.025)^{\wedge} 2=\sqrt{ } 54516.1603=3.624138$

Titik pusat ke-3 untuk Cluster 3(K3) pada iterasi 7 $B_{31}=\sqrt{ }\left((87-88.08333333)^{\wedge} 2+(84.25-87.02083333)^{\wedge} 2+\right.$ $(85.75-86.1875)^{\wedge} 2+(83.5-85.47916667)^{\wedge} 2+(84.25-$ $86.47916667)^{\wedge} 2+(86-87.5)^{\wedge} 2+(84.75-86.375)^{\wedge} 2+(86.5-$ $88.47916667)^{\wedge} 2+(87.25-86.91666667)^{\wedge} 2+(88.5-$ $87.125)^{\wedge} 2=\sqrt{ } 56018.84107=5.36081$

Setelah melakukan perhitungan pada iterasi ketujuh didapatkan hasil pengelompokan data yang sama dengan iterasi keenam dengan tidak ditemukan lagi perubahan pada kedua iterasi, anggota K1, K2 dan K3: 
a. Anggota Cluster 1 (K1) terdiri dari 3 siswa dengan Daftar Rujukan nomor urut: $(5,12,25)$.

b. Anggota Cluster 2 (K2) terdiri dari 10 siswa nomor

[1] Amirulloh, I. (2019). Pemetaan Kelompok Kerja Siswa dengan Metode Clustering K-Means dan Algoritma Greedy. Jurnal Informatika dan Rekayasa Perangkat Lunak, 1(2). DOI: http://dx.doi.org/10.36499/jinrpl.v1i2.2953

c. Anggota Cluster 3 (K3) terdiri dari 12 siswa nomor urut: $(3,4,9,10,11,13,16,19,20,21,23,24)$.

d. Mengelompokkan Data ke Masing-masing Cluster

Setelah mendapatkan hasil pengelompokan pada iterasi keenam dan dilanjutkan dengan iterasi ke tujuh tidak ada perubahan, maka proses pencarian dihentikan. Kelompok data yang termasuk ke dalam Cluster 1 (Sangat Berprestasi) dapat dilihat pada Tabel 5.

Tabel 5. Data Cluster 1 (Sangat Berprestasi)

\begin{tabular}{lccccc}
\hline No & K1 & \multicolumn{1}{c}{ K2 } & K3 & MIN & Cluster \\
\hline 5 & 3.773997 & 12.3095 & 16.27809 & 3.773997 & 1 \\
12 & 3.299832 & 9.563538 & 13.18807 & 3.299832 & 1 \\
25 & 3.290348 & 12.91277 & 16.86339 & 3.290348 & 1 \\
\hline
\end{tabular}

Kelompok data yang termasuk ke dalam Cluster 2 (Berprestasi) dapat dilihat pada Tabel 6.

Tabel 6. Data Cluster 2 (Berprestasi)

\begin{tabular}{cccccc}
\hline No & K1 & K2 & K3 & MIN & Cluster \\
\hline 1 & 12.41862 & 3.805783 & 5.326189 & 3.805783 & 2 \\
2 & 8.059242 & 5.277623 & 9.10601 & 5.277623 & 2 \\
6 & 11.46159 & 1.712557 & 5.104487 & 1.712557 & 2 \\
7 & 12.72192 & 3.891411 & 5.708257 & 3.891411 & 2 \\
8 & 11.66964 & 4.589502 & 7.167167 & 4.589502 & 2 \\
14 & 9.977753 & 3.161543 & 7.049669 & 3.161543 & 2 \\
15 & 12.83847 & 4.369433 & 6.376367 & 4.369433 & 2 \\
17 & 11.763 & 2.50928 & 4.745703 & 2.50928 & 2 \\
18 & 10.52048 & 2.106783 & 6.044728 & 2.106783 & 2 \\
22 & 13.02055 & 2.641648 & 3.900625 & 2.641648 & 2 \\
\hline
\end{tabular}

Kelompok data yang termasuk ke dalam Cluster 3 (Kurang Berprestasi) dapat dilihat pada Tabel 7.

Tabel 7. Data Cluster 3 (Kurang Berprestasi)

\begin{tabular}{clllll}
\hline No & K1 & K2 & K3 & MIN & Cluster \\
\hline 3 & 13.9244 & 4.003679 & 3.582484 & 3.582484 & 3 \\
4 & 14.585 & 5.705451 & 4.377641 & 4.377641 & 3 \\
9 & 19.4902 & 9.483892 & 5.06089 & 5.06089 & 3 \\
10 & 14.87284 & 5.574996 & 2.791849 & 2.791849 & 3 \\
11 & 13.70422 & 4.537208 & 4.408681 & 4.408681 & 3 \\
13 & 16.89592 & 8.257635 & 6.464421 & 6.464421 & 3 \\
16 & 13.12017 & 5.229496 & 4.852845 & 4.852845 & 3 \\
19 & 15.09047 & 4.57338 & 2.239646 & 2.239646 & 3 \\
20 & 15.53066 & 6.040668 & 4.507455 & 4.507455 & 3 \\
21 & 17.79142 & 7.983001 & 3.809243 & 3.809243 & 3 \\
23 & 15.34375 & 6.060857 & 3.621917 & 3.621917 & 3 \\
24 & 15.12425 & 5.31517 & 3.325024 & 3.325024 & 3 \\
\hline
\end{tabular}

Hasil cluster yang didapatkan pada Cluster 1 (K1) terdapat 3 siswa yang Sangat Berprestasi, pada Cluster 2 (K2) terdapat 10 siswa yang Berprestasi dan Cluster 3 (K3) terdapat 12 siswa yang Kurang Berprestasi.

\section{Kesimpulan}

Dalam kesimpulan tidak boleh ada referensi. Kesimpulan berisi fakta yang didapatkan. Nyatakan kemungkinan aplikasi, implikasi dan spekulasi yang sesuai. Jika diperlukan, berikan saran untuk penelitian selajutnya.
[2] Wahyudi, M., Masitha., Saragih, R., \& Solikhun. (2020). Data Mining: Penerapan Algoritma K-Means Clustering dan KMedoids Clustering. Penerbit: Yayasan Kita Menulis: kitamenulis.id.

[3] Buulolo, E. (2020). Data Mining untuk Perguruan Tinggi. Yogyakarta: Grup Penerbitan CV Budi Utama

[4] Sibuea, M. L., \& Safta, A. (2017). Pemetaan Siswa Berprestasi Menggunakan Metode K-Means Clustring. JURTEKSI (Jurnal Teknologi dan Sistem Informasi), 4(1), 85-92. DOI: https://doi.org/10.33330/jurteksi.v4i1.28

[5] Satria, W., Kusuma, P. D., \& Irawan, B. (2019). Pengelompokkan Data Mineral Di Indonesia Menggunakan Metode K-means Clustering. eProceedings of Engineering, 6(2).

[6] Hasanah, M., Defit, S., \& Nurcahyo, G. W. (2019). Implementasi Algoritma K-Means untuk Klasterisasi Peserta Olimpiade Sains Nasional Tingkat SMA. Jurnal Sistim Informasi dan Teknologi, 1(3), 29-34. DOI: https://doi.org/10.35134/jsisfotek.v1i3.7 .

[7] Aditya, A., Jovian, I., \& Sari, B. N. (2020). Implementasi KMeans Clustering Ujian Nasional Sekolah Menengah Pertama di Indonesia Tahun 2018/2019. Jurnal Media Informatika $\begin{array}{llll}\text { Budidarma, } & 4(1), & 51-58 . & \text { DOI: }\end{array}$ http://dx.doi.org/10.30865/mib.v4i1.1784 .

[8] Hartanti, N. T. (2018). Education Data Mining Untuk Menentukan Kelompok Belajar Ujian Nasional Di Smk. Jurnal Tekno Kompak, 12(2), 39-44. DOI: https://doi.org/10.33365/jtk.v12i2.123 .

[9] Sadewo, M. G., Windarto, A. P., \& Hartama, D. (2017). Penerapan Data Mining Pada Populasi Daging Ayam Ras Pedaging di Indonesia Berdasarkan Provinsi Menggunakan KMeans Clustering. InfoTekJar (Jurnal Nasional Informasi dan Teknologi Jaringan), 2(1), 60-67. DOI: https://doi.org/10.30743/infotekjar.v2i1.164

[10]Pandiangan, N., \& Buono, M. L. C. (2019). K-Means Clustering dalam Mengelompokkan Nilai Akhir Skripsi Mahasiswa. Musamus Journal of Technology \& Information, 1(02), 42-46.

[11]Luka, S. S. P., Candiasa, I. M., \& Aryanto, K. Y. E. (2019). Analisis Pembentukan Kelompok Diskusi Panel Siswa Menggunakan Algoritma Fuzzy C-Means dan K-Means. Jurnal Pendidikan Teknologi dan Kejuruan, 16(2), 267-277.

[12] Khakim, M. A., Rahmadhani, L., Purnomo, E. S. B., Wahyu, R., \& Idayani, N. A. R. (2020). Analisa Jaringan Dokumentasi dan Informasi Hukum Kementerian Tentang Teknologi Informasi Menggunakan Metode K-Means Clustering. Fountain of Informatics Journal, 5(1), 27-34. DOI: http://dx.doi.org/10.21111/fij.v5i1.4039

[13]Rachman, F., Radianto, D. O., \& Erawati, I. (2019). Pemetaan Kinerja Dosen PPNS Dengan Kriteria EPD dengan Metode KMeans Clustering. EDUSAINTEK, 3.

[14]Priyatman, H., Sajid, F., \& Haldivany, D. (2019). Klasterisasi Menggunakan Algoritma K-Means Clustering untuk Memprediksi Waktu Kelulusan Mahasiswa. Jurnal Edukasi Dan Penelitian Informatika (JEPIN), 5(1), 62. DOI: http://dx.doi.org/10.26418/jp.v5i1.29611

[15] Yunita, F. (2018). Penerapan Data Mining Menggunkan Algoritma K-Means Clustring Pada Penerimaan Mahasiswa Baru (Studi Kasus: Universitas Islam Indragiri). Jurnal Sistemasi, 7(3), 238-249. https://doi.org/10.32520/stmsi.v7i3.388

[16] Kusuma, A. S., \& Aryati, K. S. (2019). Sistem Informasi Akademik Serta Penentuan Kelas Unggulan dengan Algoritama K-Means di SMP Negeri 3 Ubud. Jurnal Sistem Informasi dan

Jurnal Sistim Informasi dan Teknologi Vol. 3 No. 1 (2021) 28-33 
Komputer Terapan Indonesia (JSIKTI), 1(3), 143-152. DOI: [18]C, I. J., Simorangkir, L., \& Puspitorini, S. (2019). Implementasi https://doi.org/10.33173/jsikti.29 .

Algoritma K-Means untuk Mengukur Performa Akademik

[17] Rustam, S., \& Annur, H. (2019). Akademik Data Mining (ADM) Mahasiswa Tiap Semester Pada Program Studi Teknik K-Means dan K-Means K-NN Untuk Mengelompokan Kelas Mata Kuliah Kosentrasi Mahasiswa Semester Akhir. ILKOM Informatika Stmik Nurdin Hamzah Jambi. Jurnal Kartika, 1(1), Jurnal Ilmiah, 11(3), 260-268. DOI: https://doi.org/10.33096/ilkom.v11i3.487.260-268 . $8-14$ 